\title{
Effects of Upper Eyelid Surgery on the Ocular Surface and Corneal Topography
}

\author{
(1) Nihan Aksu Ceylan*, (1) Barış Yeniad** \\ *İstanbul University, İstanbul Faculty of Medicine, Department of Ophthalmology, İstanbul, Turkey \\ **Eye Foundation Bayrampaşa Eye Hospital, İstanbul, Turkey
}

\begin{abstract}
Objectives: To evaluate the effect of upper eyelid surgery on ocular surface and corneal topography.

Materials and Methods: Patients who underwent upper eyelid blepharoplasty and/or blepharoptosis repair were evaluated prospectively. Tear film break-up time (TBUT), Schirmer tests, corneal staining pattern, Ocular Surface Disease Index questionnaire, corneal topography, and autorefractor parameters were measured preoperatively and at 1 day, 1 week, 1 month, 3 months, and 6 months postoperatively.

Results: Thirty-two eyes of 20 patients ( 9 male, 11 female) were included in the study. The mean age was $44.8 \pm 18.9$ years (range: 8-74). Patients were divided into the following 3 groups according to the type of surgery performed: upper eyelid blepharoplasty (group 1), upper eyelid blepharoplasty and levator advancement ptosis surgery (group 2), and levator advancement ptosis surgery (group 3). There was a significant decrease in Schirmer test results at 6 months in groups 1 and 2 but no change in group 3. TBUT values were decreased at 1 week in group $3(\mathrm{p}=0.028)$ and returned to baseline at 1 month. Corneal punctate staining was detected at 1 day and 1 week in all groups. On corneal topography, group 3 showed a significant change in K2 values ( 0.3 diopters) at 1 month ( $\mathrm{p}=0.006)$. There was no statistically significant change in autorefractor measurements postoperatively compared to preoperative values $(\mathrm{p}>0.05$ ).

Conclusion: Depending on the type of surgical procedure performed, blepharoptosis repair and upper eyelid blepharoplasty can lead to dry eye of varying severity that may persist at postoperative 6 months.
\end{abstract}

Keywords: Blepharoptosis, dry eye syndrome, corneal topography, blepharoplasty

\section{Introduction}

Blepharoptosis and dermatochalasis are common upper eyelid diseases that cause anatomic and functional impairment. Although upper eyelid surgery provides successful anatomic results, dry eye and irritative symptoms can also develop postoperatively.

Upper eyelid surgery can lead to postoperative dry eye symptoms by affecting other anatomical structures in the eyelid, such as the lacrimal gland, auxiliary tear glands, meibomian glands, and the orbicularis muscle, thereby negatively impacting tear production. Studies have reported that upper eyelid blepharoplasty and blepharoptosis repair cause dry eye symptoms and ocular irritation symptoms in patients postoperatively, but these symptoms regress within a few days or a few weeks after surgery. ${ }^{1,2,3,4}$

Pressure exerted by the eyelids causes flattening of the peripheral cornea and steepening in the central cornea, which can

Address for Correspondence: Nihan Aksu Ceylan, İstanbul University, İstanbul Faculty of Medicine, Department of Ophthalmology, İstanbul, Turkey E-mail: aksunihan@hotmail.com ORCID-ID: orcid.org/0000-0003-3724-7659

Received: 25.06 .2020 Accepted: 03.05.2021

Cite this article as: Aksu Ceylan N, Yeniad B. Effects of Upper Eyelid Surgery on the Ocular Surface and Corneal Topography. Turk J Ophthalmol 2022;52:50-56

${ }^{\circ}$ Copyright 2022 by Turkish Ophthalmological Association Turkish Journal of Ophthalmology, published by Galenos Publishing House. 
result in alterations in with-the-rule astigmatism. ${ }^{5}$ It is known that hemangioma, gold implants, and lesions such as dermoid cysts in the eyelids can affect the shape of the cornea. ${ }^{5}$ Studies have also evaluated the effects of upper eyelid surgery on corneal topography. $6,7,8,9,10,11$

The aim of the present study was to evaluate the early and late effects of different surgical interventions for blepharoptosis and dermatochalasis on the ocular surface and corneal topography.

\section{Materials and Methods}

This prospective study included 32 eyes of 20 patients with no previous surgical history or concomitant ocular disease who underwent surgery for ptosis and/or dermatochalasis in the oculoplastic surgery clinic of the İstanbul University Department of Ophthalmology between April 2014 and June 2014.

All patients in the study provided informed consent and ethical approval was obtained from the faculty ethics committee.

The patients underwent a full ophthalmologic examination including best corrected visual acuity, intraocular pressure measurement, biomicroscopic examination, and fundus examination.

Surgical technique was selected according to the patients' levator function (LF) and the coexistence of dermatochalasis with ptosis. LF was determined by asking the patient to look up and down while pressing on the brow and measuring the excursion of the upper eyelid margin. A distance $\leq 5 \mathrm{~mm}$ was regarded as poor, $6-11 \mathrm{~mm}$ as fair, and $\geq 12 \mathrm{~mm}$ as good LF. ${ }^{12}$ Frontal suspension surgery was planned for patients with poor LF, and levator resection was planned for patients with fair to good LF (>5 mm). Upper eyelid blepharoplasty was performed alone or in combination with levator resection in patients with dermatochalasis depending on whether they had concomitant ptosis.

In terms of dry eye, patients were evaluated using anesthetized and unanesthetized Schirmer tests, tear film break-up time (TBUT), corneal staining pattern according to the Oxford scale, and the Ocular Surface Disease Index (OSDI) questionnaire. OSDI scores of 0-12 were interpreted as the absence of ocular surface disease, 13-22 as mild, 23-32 as moderate, and 33-100 as severe ocular surface disease. ${ }^{13}$

Schirmer tests were performed by placing Schirmer strips (Tearstrip, Contacare, India) in the outer third of the lower lid fornix, with and without topical anesthesia (Alcaine $0.5 \%$, Alcon, Turkey), and measuring the distance wetted in millimeters after 5 minutes. Results of $\leq 10 \mathrm{~mm} / 5 \mathrm{~min}$ for the unanesthetized Schirmer test and $\leq 5 \mathrm{~mm} / 5 \mathrm{~min}$ for the anesthetized Schirmer test were considered abnormal. ${ }^{14}$

Corneal and conjunctival staining patterns were graded using the Oxford scale by asking the patient to blink several times after staining the ocular surface with a fluorescein strip (Fluostrips, Netherlands). Staining was rated as absent (0), minimal (1), mild (2), moderate (3), marked (4), or severe (5) according to the Oxford scale. ${ }^{15}$
TBUT was measured after instilling fluorescein dye as the time between the last blink and the first break in the dye on the cornea under biomicroscopic examination at x10 magnification with cobalt blue filter. ${ }^{16}$ A TBUT $<5 \mathrm{~s}$ was interpreted as suggestive of dry eye. ${ }^{17}$

Autorefractometry and corneal topography (Oculus Pentacam HR) measurements were obtained to measure the patients' refractive changes. The mean of 3 autorefractometer readings was recorded. Corneal topography was evaluated in a single measurement with high scan quality obtained after the patient blinked twice. All assessments and complete ophthalmological examination were performed preoperatively and repeated at postoperative 1 day, 1 week, 1 month, 3 months, and 6 months.

The patients were divided into 3 groups according to the surgery performed: upper eyelid blepharoplasty (group 1), upper eyelid blepharoplasty and levator resection (group 2), and levator resection (group 3). Within each group, ocular surface and refractive changes at postoperative 1 day, 1 week, 1 month, 3 months, and 6 months were evaluated by comparing with preoperative values. Changes in refractive values of $0.2 \mathrm{D}$ or greater were considered clinically significant because they may cause noticeable visual complaints. ${ }^{5}$

\section{Statistical Analysis}

All results were statistically analyzed using SPSS software (version 21.0, IBM Corp, Armonk, NY, USA). Results were compared using the nonparametric Friedman test, and those with significant results in the Friedman test were evaluated by post-hoc analysis. In the statistical analysis, p values of $<0.05$ were regarded as significant, $<0.001$ as highly significant, and $>0.05$ as insignificant.

\section{Results}

Thirty-two eyes of 20 patients were included in the study. There were 11 female patients and 9 male patients, and the mean age was $44.8 \pm 18.9$ years (range, $8-74$ ). Twelve patients underwent bilateral surgery and 8 underwent unilateral surgery.

According to the surgery performed, 12 eyes were included in group 1, 8 eyes in group 2, and 12 eyes in group 3.

Table 1 shows the comparison of pre- and postoperative unanesthetized Schirmer test values within the groups. In group 2, values were lower at all postoperative visits compared to preoperative values, with statistically significant decreases at postoperative 1 day, 1 week, and 6 months $(\mathrm{p}=0.006$, $\mathrm{p}=0.025$, and $\mathrm{p}=0.003$, respectively). There were no significant postoperative changes in groups 1 or 3 ( $\mathrm{p}>0.05)$.

The comparison of the groups' pre- and postoperative anesthetized Schirmer test results is shown in Table 2. In group 1 , there was no significant change compared to preoperative measurements, although the change between postoperative 1 day and 3 months was statistically significant $(\mathrm{p}=0.008)$. In group 2 , all postoperative values were lower than preoperative values, with significant decreases at 1 day, 1 month, and 6 months ( $\mathrm{p}=0.013, \mathrm{p}=0.008$, and $\mathrm{p}=0.001$, respectively). In group 3, 
we detected no significant difference between preoperative and postoperative measurements ( $\mathrm{p}>0.05$ ).

Changes in corneal punctate staining patterns according to the Oxford scale observed in the operated eyes are shown in Table 3. Corneal punctate staining was not observed in any eye preoperatively, while eyes in all groups exhibited corneal punctate staining of varying severity according to the Oxford scale at postoperative 1 day and 1 week. In group 2, corneal punctate staining persisted at 6 months.

Table 4 shows the comparison of preoperative and postoperative TBUT values within the groups. There was no statistically significant change in postoperative TBUT compared to preoperative values in groups 1 and 2 . In group 3 ,
TBUT was significant decreased at postoperative 1 week when compared with preoperative values $(\mathrm{p}=0.028)$ but returned to the preoperative level at postoperative 1 month.

Table 5 shows the comparison of preoperative and postoperative OSDI scores within the three groups. Although none of the patients were diagnosed with dry eye preoperatively, their preoperative OSDI questionnaire scores indicated mild, moderate, and severe ocular surface disease in 3, 3, and 9 patients, respectively, while the other 5 patients had no ocular surface disease. Postoperative OSDI scores decreased in group 1 but not significantly ( $p>0.05$ ), while significantly decreases were observed in groups 2 and 3 at postoperative 6 months compared to preoperative values $(\mathrm{p}=0.005$ and $\mathrm{p}=0.012$, respectively).

\begin{tabular}{|c|c|c|c|c|c|c|}
\hline $\begin{array}{l}\text { Unanesthetized } \\
\text { Schirmer test }\end{array}$ & $\begin{array}{l}\text { Group } 1 \\
\text { mean } \pm \text { SD }\end{array}$ & p value & $\begin{array}{l}\text { Group } 2 \\
\text { mean } \pm \text { SD }\end{array}$ & p value & $\begin{array}{l}\text { Group } 3 \\
\text { mean } \pm \text { SD }\end{array}$ & p value \\
\hline Preop & $24 \pm 8$ & \multirow{6}{*}{0.053} & $18 \pm 3$ & \multirow{6}{*}{0.001} & $22 \pm 8$ & \multirow{6}{*}{0.732} \\
\hline Postop 1 day & $22 \pm 7.7$ & & $11 \pm 5.2^{\mathrm{a}}$ & & $25 \pm 10.4$ & \\
\hline Postop 1 week & $19 \pm 8$ & & $9 \pm 6^{\mathrm{b}}$ & & $23 \pm 9$ & \\
\hline Postop 1 month & $23 \pm 8$ & & $11 \pm 6$ & & $23 \pm 7$ & \\
\hline Postop 3 months & $19 \pm 9$ & & $11 \pm 6$ & & $20 \pm 6$ & \\
\hline Postop 6 months & $25 \pm 9$ & & $11 \pm 6^{c}$ & & $18 \pm 8$ & \\
\hline \multicolumn{7}{|c|}{$\begin{array}{l}{ }^{2} \text { The difference between preoperative and postoperative } 1 \text { day values was significant in post-hoc analysis }(\mathrm{p}=0.006) \text {. } \\
{ }^{\circ} \text { The difference between preoperative and postoperative } 1 \text { week values was significant in post-hoc analysis }(\mathrm{p}=0.025) \text {. } \\
\text { 'The difference between preoperative and postoperative } 6 \text { months values was significant in post-hoc analysis }(\mathrm{p}=0.003\end{array}$} \\
\hline
\end{tabular}

Table 2. Comparison of pre- and postoperative anesthetized Schirmer test results $(\mathrm{mm} / 5 \mathrm{~min})$ within the surgical groups

\begin{tabular}{|c|c|c|c|c|c|c|}
\hline $\begin{array}{l}\text { Unanesthetized } \\
\text { Schirmer test }\end{array}$ & $\begin{array}{l}\text { Group } 1 \\
\text { mean } \pm \text { SD }\end{array}$ & p value & $\begin{array}{l}\text { Group } 2 \\
\text { mean } \pm \text { SD }\end{array}$ & p value & $\begin{array}{l}\text { Group } 3 \\
\text { mean } \pm \text { SD }\end{array}$ & p value \\
\hline Preop & $20 \pm 6$ & \multirow{6}{*}{0.041} & $15 \pm 3$ & \multirow{6}{*}{0.001} & $13 \pm 7$ & \multirow{6}{*}{0.716} \\
\hline Postop 1 day & $17 \pm 6.2$ & & $6 \pm 5.6^{b}$ & & $14 \pm 7.2$ & \\
\hline Postop 1 week & $14 \pm 7$ & & $8 \pm 6$ & & $15 \pm 8$ & \\
\hline Postop 1 month & $16 \pm 7$ & & $8 \pm 5^{c}$ & & $17 \pm 7$ & \\
\hline Postop 3 months & $13 \pm 6^{a}$ & & $10 \pm 4$ & & $14 \pm 7$ & \\
\hline Postop 6 months & $16 \pm 6$ & & $6 \pm 6^{\mathrm{d}}$ & & $11 \pm 7$ & \\
\hline $\begin{array}{l}\text { Preop: Preoperative, Pos } \\
\text { "The difference between } \\
\text { 'The difference between } \\
\text { 'The difference between } \\
\text { dThe difference between }\end{array}$ & $\begin{array}{l}\text { perative, SD: Stan } \\
\text { tive } 1 \text { day and } 3 \mathrm{~m} \\
\text { ive and postoperat } \\
\text { ive and postoperat } \\
\text { ive and postoperat }\end{array}$ & $\begin{array}{l}\text { vas significan } \\
\text { s was signific } \\
\text { lues was sign } \\
\text { alues was sig }\end{array}$ & $\begin{array}{l}\text { hoc analysis ( } \mathrm{p}=0 \\
\text { st-hoc analysis ( } \mathrm{p} \\
\text { post-hoc analysi } \\
\text { in post-hoc analys }\end{array}$ & & & \\
\hline
\end{tabular}

Table 3. Change in corneal punctate staining patterns in the surgical groups $(n=$ number of eyes)

\begin{tabular}{|l|l|l|l|}
\hline Corneal punctate staining & Group 1 (n=12) & Group 2 (n=8) & Group 3 (n=12) \\
\hline Preop & 0 & 0 & 0 \\
\hline Postop 1 day & 1 & 5 & 3 \\
\hline Postop 1 week & 2 & 6 & 3 \\
\hline Postop 1 month & 0 & 4 & 0 \\
\hline Postop 3 months & 0 & 4 & 1 \\
\hline Postop 6 months & 0 & 3 & 0 \\
\hline Preop: Preoperative, Postop: Postoperative & & & \\
\hline
\end{tabular}


When autorefractometric spherical values were examined, none of the groups showed a significant change in postoperative spherical values compared to preoperative values $(\mathrm{p}>0.05)$. In group 1 , spherical values were decreased at 1 week (mean $0.88 \pm 0.71 \mathrm{D})$ and increased at 3 months (mean $1.25 \pm 0.73 \mathrm{D}$ ) when compared with preoperative values (mean $1 \pm 0.70 \mathrm{D})$, with a significant difference between 1 week and 3 months $(0.37 \mathrm{D}$ change, $\mathrm{p}<0.05)$.

"The postoperative autorefractometric cylindrical values of the surgical groups are shown in Table 6. Compared to preoperative values, autorefractometric cylindrical values showed changes of $0.25 \mathrm{D}$ starting from postoperative day 1 in group 1, at postoperative 1 week and 1 month in group 2, and at postoperative 1 day in group 3, but the differences were not statistically significant $(\mathrm{p}>0.05)$. Cylindrical axis values increased by $10^{\circ}$ or more at postoperative 1 month in group 1 , at 6 months in group 2, and starting from 1 week in group 3, but the differences were not statistically significant ( $p>0.05)$.

The surgical groups' postoperative keratometric values (K1, $\mathrm{K} 2$ ) on corneal topography were compared with preoperative values. Compared to preoperative values, $\mathrm{K} 1$ changed by $0.2 \mathrm{D}$ or more at postoperative 1 day in group 1 , from postoperative 1 month in group 2, and at postoperative 1 month in group 3, but the differences were not statistically significant $(p>0.05)$. $\mathrm{K} 2$ values in groups 1 and 2 did not change by $0.2 \mathrm{D}$ or more or show any statistically significant differences. In group 3, K2

Table 4. Comparison of pre- and postoperative tear film break-up time (TBUT) measurements within the surgical groups

\begin{tabular}{|c|c|c|c|c|c|c|}
\hline TBUT (s) & $\begin{array}{l}\text { Group } 1 \\
\text { mean } \pm \text { SD }\end{array}$ & p value & $\begin{array}{l}\text { Group } 2 \\
\text { mean } \pm \text { SD }\end{array}$ & p value & \begin{tabular}{|l} 
Group 3 \\
mean \pm SD
\end{tabular} & p value \\
\hline Preop & $10 \pm 3$ & \multirow{6}{*}{0.086} & $6 \pm 3$ & \multirow{6}{*}{0.074} & $8 \pm 2$ & \multirow{6}{*}{0.001} \\
\hline Postop 1 day & $9.5 \pm 2.8$ & & $4.5 \pm 2.9$ & & $6.5 \pm 3.3$ & \\
\hline Postop 1 week & $10 \pm 4$ & & $5 \pm 4$ & & $5 \pm 2^{a}$ & \\
\hline Postop 1 month & $10 \pm 3$ & & $5 \pm 4$ & & $8 \pm 2$ & \\
\hline Postop 3 months & $9 \pm 3$ & & $6 \pm 3$ & & $9 \pm 2$ & \\
\hline Postop 6 months & $10 \pm 2$ & & $6 \pm 4$ & & $8 \pm 2$ & \\
\hline
\end{tabular}

Table 5. Comparison of pre- and postoperative Ocular Surface Disease index (OSDI) scores within the surgical groups

\begin{tabular}{|c|c|c|c|c|c|c|}
\hline OSDI score & $\begin{array}{l}\text { Group } 1 \\
\text { median (min-max) }\end{array}$ & p value & $\begin{array}{l}\text { Group } 2 \\
\text { median (min-max) }\end{array}$ & p value & $\begin{array}{l}\text { Group } 3 \\
\text { median (min-max) }\end{array}$ & p value \\
\hline Preop & $23.9(2.1-68.1)$ & \multirow{6}{*}{0.208} & $53(8.3-58.3)$ & \multirow{6}{*}{0.021} & $32.3(0-77.3)$ & \multirow{6}{*}{0.024} \\
\hline Postop 1 day & $4.2(0-79.5)$ & & $56.3(4.2-64.6)$ & & $19.5(4.6-63.6)$ & \\
\hline Postop 1 week & $3.1(0-84.1)$ & & $35.3(6.3-77.1)$ & & $14(0-68.2)$ & \\
\hline Postop 1 month & $13.5(0-83.3)$ & & $20.4(2.1-70.1)$ & & $12.5(0-50)$ & \\
\hline Postop 3 months & $17.7(2.1-79.2)$ & & $28.4(0-70.8)$ & & $15.9(0-40.9)$ & \\
\hline Postop 6 months & $6.3(2.1-95.5)$ & & $12.5(2.1-64.6)^{a}$ & & $9.5(0-40.9)^{b}$ & \\
\hline $\begin{array}{l}\text { Preop: Preoperative, } \\
\text { a'The difference betwe } \\
{ }^{b} \text { The difference betw }\end{array}$ & $\begin{array}{l}\text { Postoperative, SD: Standard d } \\
\text { operative and postoperative } 6 \\
\text { operative and postoperative } 6\end{array}$ & on values was $s$ & $\begin{array}{l}\text { in post-hoc analysis }(\mathrm{p}=0.00 \\
\text { in post-hoc analysis }(\mathrm{p}=0.01\end{array}$ & & & \\
\hline
\end{tabular}

Table 6. Comparison of pre- and postoperative autorefractometric cylindrical values within the surgical groups

\begin{tabular}{|c|c|c|c|c|c|c|}
\hline Cylindrical values (D) & $\begin{array}{l}\text { Group } 1 \\
\text { mean } \pm \text { SD }\end{array}$ & p value & $\begin{array}{l}\text { Group } 2 \\
\text { mean } \pm \text { SD }\end{array}$ & p value & $\begin{array}{l}\text { Group } 3 \\
\text { mean } \pm \text { SD }\end{array}$ & p value \\
\hline Preop & $-0.50 \pm 1.12$ & \multirow{6}{*}{0.284} & $-1.13 \pm 0.28$ & \multirow{6}{*}{0.777} & $-0.88 \pm 0.73$ & \multirow{6}{*}{0.716} \\
\hline Postop 1 day & $-0.75 \pm 1.08$ & & $-1.13 \pm 0.49$ & & $-1.13 \pm 0.91$ & \\
\hline Postop 1 week & $-0.75 \pm 1.08$ & & $-0.88 \pm 0.30$ & & $-0.88 \pm 1.23$ & \\
\hline Postop 1 month & $-0.75 \pm 1.04$ & & $-0.75 \pm 0.53$ & & $-0.88 \pm 0.64$ & \\
\hline Postop 3 months & $-0.75 \pm 1.19$ & & $-1.13 \pm 0.52$ & & $-0.75 \pm 0.47$ & \\
\hline Postop 6 months & $-0.75 \pm 1.23$ & & $-1 \pm 0.40$ & & $-0.75 \pm 0.74$ & \\
\hline
\end{tabular}


values changed by $0.2 \mathrm{D}$ or more compared to preoperative values starting at postoperative 1 week, with a statistically significant difference $(0.3 \mathrm{D})$ at postoperative 1 month compared to the preoperative values $(\mathrm{p}=0.006)$.

\section{Discussion}

Upper eyelid blepharoplasty and blepharoptosis repair are known to cause dry eye symptoms and ocular irritation findings in the postoperative period. ${ }^{1,2,3,4}$

Black et al. ${ }^{18}$ determined that there was a temporary reduction in eyelid sensation after upper eyelid surgery and attributed this decrease to damage to the trigeminal nerve branches that receive sensation from the upper eyelid during incision and dissection. In addition to direct nerve damage, it is also known that ocular surface sensation can be diminished because of proinflammatory cytokines and opioid peptides, which increase as a result of inflammation. ${ }^{19,20}$ Reduced ocular surface sensation results in decreased tear production. ${ }^{19}$

In a study evaluating ocular surface sensation and tear production in patients who underwent upper eyelid blepharoplasty or blepharoptosis repair, Kim et al. ${ }^{3}$ reported that ocular surface sensation was reduced in all patients at postoperative 1 day and returned to preoperative values at 1 month. Contrary to other studies, they observed an increase in Schirmer test results at postoperative 1 month. Yan et al. ${ }^{21}$ also reported an increase in Schirmer 1 and noninvasive TBUT measurements 1 week after upper eyelid blepharoplasty in young patients. Unculu et al. ${ }^{4}$ prospectively evaluated dry eye parameters in 11 patients who underwent transcutaneous levator resection and found a significant decrease in Schirmer 1 test values at postoperative 1 month.

In the present study, we detected no significant change in postoperative Schirmer test results in the group that underwent only levator surgery. The statistically significant decrease observed in the blepharoplasty group suggests a mechanism associated with the orbicularis muscle. Orbicularis muscle excision is believed to weaken the orbicularis muscle, reduce the blinking reflex, and decrease corneal sensation and tear secretion due to damage to trigeminal nerve branches, resulting in a decrease in basal and reflex tears. Zloto et al. ${ }^{22}$ performed upper eyelid blepharoplasty without orbicularis muscle excision and observed no change in objective and subjective dry eye parameters when preoperative and postoperative tests were compared. This supports the hypothesis regarding the role of the orbicularis muscle in the development of dry eye. In addition, the decrease in Schirmer test values observed at postoperative 1 day may be associated with a reduction in corneal sensitivity caused by proinflammatory cytokines and opioid peptides.

In previous studies with short-term postoperative followup, it was reported that dry eye findings appeared in the early postoperative period but resolved within a few weeks or months. ${ }^{1,21,23}$ Demirok et al. ${ }^{24}$ evaluated late Schirmer test, TBUT, and OSDI values in 81 patients who were followed for at least 6 months after upper eyelid blepharoplasty and compared them with preoperative values. They reported no change in Schirmer test and OSDI scores but a statistically significant decrease in TBUT values at postoperative 6 months and beyond. However, no change in TBUT values was observed after upper eyelid blepharoplasty in two studies by Shao et al. ${ }^{23}$ and Soares et al. ${ }^{25}$ Unculu et al. ${ }^{4}$ also detected no change in TBUT after levator resection surgery.

In contrast to these studies, we found that TBUT was significantly decreased at postoperative 1 week and returned to preoperative values after postoperative 1 month in the group that underwent only levator surgery. We thought that TBUT, which is associated with tear film stability, may have been temporarily reduced as a result of decreased blinking reflex, insufficient blinking, and transient meibomian gland dysfunction caused by perioperative local anesthetics and postoperative inflammation, but this effect was not observed in all groups.

Unlike previous studies, the patients in our study were followed up at regular intervals until postoperative 6 months, and the significant reduction in Schirmer test results and corneal punctate staining at postoperative 6 months demonstrated that dry eye findings persisted in the postoperative long term.

A study by Vold et al. ${ }^{26}$ showed that patients with dermatochalasis developed subjective dry eye symptoms that regressed after upper eyelid blepharoplasty. Yan et al. ${ }^{21}$ reported that the postoperative OSDI scores of patients who underwent upper eyelid surgery changed significantly postoperatively, independent of dry eye findings. Similar to the study conducted by Vold et al. ${ }^{26}$, we observed in this study that none of the patients had preoperative dry eye signs, but their OSDI scores suggested the presence of subjective dry eye symptoms. In our study, the decrease in OSDI scores at postoperative 6 months in the combined surgery and levator surgery groups was not correlated with Schirmer test results, consistent with the study by Yan et al. ${ }^{21}$, and we thought the decrease in OSDI may have been related to postoperative patient satisfaction.

Studies have also evaluated the effects of upper eyelid surgery on corneal topography. ${ }^{5,6,7,8,9,10,11,27}$ In a study by Zinkernager et al. $^{5}$, patients undergoing surgery for dermatochalasis or ptosis were divided into three groups according to the surgery performed: ptosis repair by levator surgery, blepharoplasty performed with skin-only removal, and blepharoplasty with skin and fat pad removal. At postoperative 3 months, they detected astigmatic changes of $0.19 \mathrm{D}$ in the blepharoplasty with fat pad reduction group and $0.25 \mathrm{D}$ in the ptosis repair by levator surgery group, while no statistically significant change was detected in the astigmatic axis. In the study, astigmatic changes of $0.2 \mathrm{D}$ or greater were considered clinically significant because based on the authors' experience, changes of this magnitude could affect visual acuity and be noticed by the patient.

In a study by Brown et al. ${ }^{27}$ evaluating blepharoplasty and ptosis surgeries, patients in the ptosis group had a mean change of $0.6 \mathrm{D}$, with $30 \%$ having changes greater than $1 \mathrm{D}$. In the blepharoplasty group, keratometry showed a mean change of $0.55 \mathrm{D}$, and only $11 \%$ of patients had a change greater than $1 \mathrm{D}$. 
Mean astigmatic change after upper eyelid blepharoplasty was reported as $0.22 \mathrm{D}$ in a study by Altin Ekin et al. ${ }^{8}$ and 0.15 $\mathrm{D}$ in a study by Simsek et al. ${ }^{9}$ Savino et al. ${ }^{7}$ examined corneal topographic changes after ptosis surgery and found a change of $0.15 \mathrm{D}$ in mean keratometry values, $0.26 \mathrm{D}$ in astigmatism, and $10^{\circ}$ in mean axis values. On the other hand, Dogan et al. ${ }^{10}$ reported detecting postoperative changes only in $\mathrm{K} 2$ values after upper eyelid blepharoplasty, with no changes in other keratometric values.

Unlike other studies, we evaluated autorefractometric measurements in addition to corneal topography in the present study. We detected no significant postoperative changes in autorefractometric spherical and cylindrical values compared to preoperative values. As observed by Dogan et al.$^{10}$ in patients undergoing upper eyelid blepharoplasty, the only significant difference in corneal topography was a change of $0.3 \mathrm{D}$ in $\mathrm{K} 2$ values at postoperative 1 month in the group undergoing levator surgery, but this change did not persist at postoperative 3 and 6 months. Similar to the studies by Dogan et al. ${ }^{10}$ and Nalc1 et al. ${ }^{11}$, we detected no other significant postoperative changes in other keratometric values.

Previous studies have suggested that upper eyelid surgery changes the pressure exerted by the eyelid on the cornea and that the resulting change in cornea shape may cause refractive changes. ${ }^{5,7,8}$ However, as these patients were evaluated at a single postoperative visit, it is not clear whether the refractive changes persisted at later visits. Şimşek et al. ${ }^{9}$ assessed corneal topography at postoperative 1 and 3 months and detected astigmatic changes at both time points. In our study, patients were followed up until postoperative 6 months, and although the group undergoing levator surgery showed a change at postoperative 1 month, we observed no astigmatic changes at subsequent visits, leading us to conclude that upper eyelid surgery did not permanently alter corneal topography. As studies have yielded different results regarding the effect of upper eyelid surgery on corneal keratometric values, further studies with larger patient groups are needed.

\section{Study Limitations}

Although we prospectively evaluated the effects of different upper eyelid surgeries on corneal topography and the ocular surface, prospective studies with larger patient samples are needed because of the small number of patients included in this study. In addition, although our follow-up period was longer than in previous studies, even longer postoperative follow-up to evaluate whether dry eye findings are temporary would further contribute to the literature.

\section{Conclusion}

Depending on the surgical procedure performed, ptosis surgery and upper lid blepharoplasty can lead to dry eye of varying severity that may persist at postoperative 6 months. Assessment of corneal topography in patients who underwent upper eyelid surgery showed that levator surgery could cause temporary refractive changes, whereas upper eyelid blepharoplasty was not associated with postoperative keratometric change.

\section{Acknowledgements}

We would like to thank Lale Közer Bilgin for her support and knowledge during the conducting of this study.

Ethics

Ethics Committee Approval: Approval for the study was obtained from the Ethics Committee of Istanbul University, Istanbul Faculty of Medicine. (approval number: 09, date: 09.05.2014).

Informed Consent: Obtained.

Peer-review: Internally peer reviewed.

\section{Authorship Contributions}

Surgical and Medical Practices: N.A.C., B.Y., Concept: N.A.C., B.Y., Design: N.A.C., B.Y., Data Collection or Processing: N.A.C., Analysis or Interpretation: N.A.C., B.Y., Literature Search: N.A.C., Writing: N.A.C.

Conflict of Interest: No conflict of interest was declared by the authors.

Financial Disclosure: The authors declared that this study received no financial support.

\section{References}

1. Rees TD, LaTrenta GS. The role of Schirmer's test and orbital morphology in predicting dry eye syndrome after blepharoplasty. Plast Reconstr Surg. 1988;82:619-625.

2. McKinney P, Buyon M. The value of tear film breakup and Schirmer's tests in preoperative blepharoplasty evaluation. Plast Reconstr Surg. 1999;104:566569.

3. Kim HH, DePavia CS, Yen MT. Effects of upper eyelid blepharoplasty on ocular surface sensation and tear production. Can J Ophthalmol. 2007;42:739742 .

4. Unculu RB, Yıldız HE, Serin D, Vural ET, Buttanrı İB. Evaluation of Dry Eye Parameters and Meibomian Gland Morphology in Patients Who Underwent Transcutaneous Levator Resection. Turkiye Klinikleri Journal of Ophthalmol. 2018;27:255-259.

5. Zinkeragel MS, Ebneter A, Ammann-Rauch D. Effect of upper eyelid surgery on corneal topography. Arch Ophthalmol. 2007;125:1610-1612.

6. Kim YK, In JH, Jang SY. Changes in corneal curvature after upper eyelid surgery measured by corneal topography. Journal of Craniofacial Surgery. 2016;27:e235-e238.

7. Savino G, Battendieri R, Riso M, Traina S, Poscia A, D'Amico G, Caporossi A. Corneal topographic changes after eyelid ptosis surgery. Cornea. 2016;35:501505 .

8. Altin Ekin M, Karadeniz Ugurlu, S. Prospective analysis of visual function changes in patients with dermatochalasis after upper eyelid blepharoplasty. European journal of Ophthalmology. 2020;30:978-984.

9. Simsek IB, Yilmaz B, Yildiz S, Artunay O. Effect of upper eyelid blepharoplasty on vision and corneal tomographic changes measured by pentacam. Orbit. 2015;34 263-267.

10. Dogan E, Akbas Kocaoglu F, Yalniz-Akkaya Z, Elbeyli A, Burcu A, Ornek F. Scheimpflug imaging in dermatochalasis patients before and after upper eyelid blepharoplasty. Seminars in Ophthalmology, Informa Healthcare. 2015;30:193-196.

11. Nalcı H, Hoşal MB, Gündüz ÖU. Effects of Upper Eyelid Blepharoplasty on Contrast Sensitivity in Dermatochalasis Patients. Turk J Ophthal. 2020;50:151.

12. Albert DM. Albert \& Jakobiec's principles and practice of ophthalmology (Vol. 4). JW Miller, DT Azar, BA Blodi, JE Cohan, T Perkins (Eds.). Philadelphia, PA: Saunders Elsevier, 2008. 
13. Walt J. Ocular Surface Disease Index (OSDI) Administration and Scoring Manual. Irvine, CA: Allergan, Inc; 2004.

14. Chiang B, Asbell PA, Franklin B. Phenol red thread test and Schirmer test for tear production in normal and dry eye patients. Invest Ophthalmol Vis Sci. 1988;29:337.

15. Bron A, Evans VE, Smith JA. Grading of corneal and conjunctival staining in the context of other dry eye tests. Cornea. 2003;22:640-650.

16. Pflugfelder SC, Tseng SC, Sanabria O, Kell H, Garcia CG, Felix C, Reis BL. Evaluation of subjective assessments and objective diagnostic tests for diagnosing tear-film disorders known to cause ocular irritation. Cornea. 1998; $17: 38$

17. Doğru M. New Developments in Dry Eye Diagnosis. MN Oftalmoloji. 2016;23(Suppl 1):15-19.

18. Black EH, Gladstone GJ. Eyelid sensation after supratarsal lid crease incision. Ophthal Plast Reconstr Surg. 2002;18:45-49.

19. Xu KP, Yagi Y, Tsubota K. Decrease in corneal sensitivity and change in tear function in dry eye. Cornea. 1996;15:235-239.

20. Scott KR, Tse DT, Kronish JW. Vertically oriented upper eyelid nerves: a clinical, anatomical and immunohistochemical study. Ophthalmology. 1992;99:222-226
21. Yan Y, Zhou Y, Zhang S, Cui C, Song X, Zhu X, Fu Y. Impact of full-incision double-eyelid blepharoplasty on tear film dynamics and dry eye symptoms in young Asian females. Aesthetic Plastic Surgery. 2020:1-8.

22. Zloto O, Matani A, Prat D, Leshno A, Simon GB. The effect of a ptosis procedure compared to an upper blepharoplasty on dry eye syndrome. American Journal of Ophthalmology. 2020;212:1-6.

23. Shao C, Fu Y, Lu L, Chen J, Shen Q, Zhu H, Fan X. Dynamic changes of tear fluid after cosmetic transcutaneous lower blepharoplasty measured by optical coherence tomography. Am J Ophthalmol. 2014;158:55-63.

24. Demirok G, Gürdal C, Atik E, Akbaş Kocaoğlu F, Örnek F. The Evaluation of Long-term Results and Patient Satisfaction after Upper Eyelid Blepharoplasty. MN Oftalmoloji. 2017;24:138-142.

25. Soares A, Faria-Correia F, Franqueira N, Ribeiro S. Effect of superior blepharoplasty on tear film: objective evaluation with the Keratograph $5 \mathrm{M} \mathrm{-} \mathrm{a}$ pilot study. Arq Bras Oftalmol. 2018;81:471-474.

26. Vold, SD, Carroll RP, Nelson JD. Dermatochalasis and dry eye. Am J Ophthalmol 1993;115:216-220.

27. Brown MS, Siegel IM, Lisman RD. Prospective analysis of change in corneal topography after upper eyelid surgery. Ophthal Plast Reconstr Surg. 1999;15:378-383. 